\title{
Energy Recovery Strategy Numerical Simulation for Dual Axle Drive Pure Electric Vehicle Based on Motor Loss Model and Big Data Calculation
}

\author{
Huiyuan Xiong, ${ }^{1,2}$ Xionglai Zhu, ${ }^{1}$ and Ronghui Zhang $\mathbb{D}^{1,3}$ \\ ${ }^{1}$ School of Intelligent Systems Engineering, Sun Yat-sen University, Guangzhou, Guangdong 510006, China \\ ${ }^{2}$ Institute of Dongguan, Sun Yat-sen University, Dongguan, Guangdong 523808, China \\ ${ }^{3}$ Guangdong Key Laboratory of Intelligent Transportation System, Sun Yat-sen University, Guangzhou, Guangdong 510275, China
}

Correspondence should be addressed to Ronghui Zhang; zrh1981819@126.com

Received 16 May 2018; Revised 25 June 2018; Accepted 28 June 2018; Published 26 August 2018

Academic Editor: Wei Xiang

Copyright ( 2018 Huiyuan Xiong et al. This is an open access article distributed under the Creative Commons Attribution License, which permits unrestricted use, distribution, and reproduction in any medium, provided the original work is properly cited.

\begin{abstract}
Aiming at the braking energy feedback control in the optimal energy recovery of the two-motor dual-axis drive electric vehicle $(\mathrm{EV})$, the efficiency numerical simulation model based on the permanent magnet synchronous motor loss was established. At the same time, under different speed and braking conditions, based on maximum recovery efficiency and data calculation of motor system, the optimization motor braking torque distribution model was established. Thus, the distribution rule of the power optimization for the front and rear electric mechanism was obtained. This paper takes the Economic Commission of Europe (ECE) braking safety regulation as the constraint condition, and finally, a new regenerative braking torque distribution strategy numerical simulation was developed. The simulation model of Simulink and CarSim was established based on the simulation object. The numerical simulation results show that under the proposed strategy, the average utilization efficiency of the motor system is increased by 3.24\% compared with the I based braking force distribution strategy. Moreover, it is $9.95 \%$ higher than the maximum braking energy recovery strategy of the front axle. Finally, through the driving behavior of the driver obtained from the big data platform, we analyze how the automobile braking force matches with the driver's driving behavior. It also analyzes how the automobile braking force matches the energy recovery efficiency. The research results in this paper provide a reference for the future calculation of braking force feedback control system based on big data of new energy vehicles. It also provides a reference for the modeling of brake feedback control system.
\end{abstract}

\section{Introduction}

1.1. Problem and Motivation. Braking energy recovery is an important means to improve the energy efficiency of electric vehicles. Recovery energy is closely related to energy recovery strategy [1]. At present, there are many researches on the energy recovery strategy for uniaxially driven electric vehicles. In the coming period, the development of the electric vehicle industry must be breakthroughs and innovations in the direction of intellectualization and data. The process of data analysis mainly includes vehicle traffic data, driving behavior evaluation data, vehicle modeling data, and battery modeling data. We can improve the mileage of electric vehicles by using large data technology, and provide a reliable basis for the research of the parts and control strategies of electric vehicles.

The advantages of zero emission and zero pollution for electric vehicles have increasingly become the key supportive development direction for major automotive countries [2, 3]. The difference between electric cars and traditional cars is due to the use of batteries as energy sources. Therefore, if we want to improve the mileage of electric vehicles, its most important key lies in the development of battery technology. However, there is still a big gap between the requirements of high energy density and low prices [4]. As a unique energysaving method for electric vehicles, braking energy recovery has always been the focus of many scholars. By establishing a braking energy recovery storage system in an electric 
vehicle, it can meet the two requirements when it recharges the energy, which is the requirement of large current and high power $[5,6]$. For the problem of short driving range with pure electric vehicles, braking energy recovery technology can improve its endurance [7-10]. In the braking process, the motor is controlled as a generator in the state of power generation, converts part of the entire vehicle's kinetic energy into electrical energy, and ultimately returns it to be stored in a battery pack or a super capacitor $[11,12]$. For a biaxially driven pure electric vehicle, to achieve maximum recovery of braking energy, its braking energy recovery capability and efficiency are affected by many factors such as motor speed, torque, and battery pack state of charge (SOC) [13]. Therefore, on the premise of ensuring safety and braking comfort, a reasonable strategy for regenerative braking must be established to solve the distribution problem of front and rear axle braking force. Coordinating the relationship between regenerative braking and mechanical braking on the front and rear axles to avoid greater deceleration and deceleration rate change. As a result, the comfort is reduced, and the maximum energy recovered cannot be guaranteed $[14,15]$. At present, big data are used in the direction of electric vehicle, mainly concentrated in the battery module. By analyzing a large number of drivers' long driving mode, road conditions, weather conditions, and so on, the influence of the electric vehicle at different driving speed, acceleration, and temperature on the energy consumption rate is calculated. However, in the estimation of electric vehicle mileage, it does not consider the influence of motor control strategy $[16,17]$. Therefore, it is necessary to study the regenerative braking strategy of a dual-axis drive electric vehicle [18].

1.2. Related Works. Literature [19-21] proposed a regenerative braking control method based on maximizing the energy recovery of ripple correlation control (RCC). The braking energy recovered by this method is increased by $20 \%$ compared with the traditional regenerative braking control method. In [22-25], to recover the braking energy as much as possible and appropriately reduce the braking stability, the front and rear axle actual brake force distribution lines are paralleled to the I curve outside. Literature [26-28] uses a new type of energy recovery system on electric buses. Simulation analysis and experimental studies have shown that braking energy can be more effective. The main purpose of the above research is to allocate excessive braking force to the electric drive shaft, so as to improve the energy recovery. It is not applicable to the dual-axis driving pure electric vehicle. Compared to single-drive electric vehicles, two-axis drive electric vehicles can output electric braking force on each axis, which can better ensure braking stability, effectively reduce the impact of antilock dead brake system (ABS) on energy recovery $[29,30]$, and have higher energy recovery potential. Currently, there are relatively few researches on the energy recovery strategy for dual-axis driving pure electric vehicles. The literature [31-33] studies the characteristics of mechanical braking and electric braking, and it proposes that in the process of regenerative braking feedback, single motor control can be used or multimotor coordinated control. Literature [34-36] analyzed the vehicle control strategy and energy-saving potential of an electric vehicle dualmotor drive system, and it used the dynamic and static functions to optimize the motor operating mode. In [37], taking into account the safety of braking, both taking into account the maximum recovery of regenerative braking energy, an improved dual-motor electric vehicle regenerative braking control strategy was designed by adjusting the regenerative braking force and the mechanical braking force. Most of the existing dual-drive braking strategies are based on the distribution between the regenerative braking force and the mechanical braking force on each axis. With regard to the application of big data in electric vehicles, the scheduling capacity prediction method of multitimescale electric vehicle cluster based on large data is proposed in [38], solves the problem of large capacity data storage, and analyzes the dispatching capability of electric vehicle cluster. Literature [39] uses unsupervised learning algorithm to train a large number of operational data, which was collected by the actual electric vehicle system to form driver behavior habits. The proposed framework can be applied to the new EV design, intelligent transportation system (ITS), and large data analysis in the field of automobile and urban computing. With the vigorous development of the new energy vehicle industry, the new energy automotive industry will enter the era of big data in the future. New energy vehicles have been moving towards comprehensive data and intelligence in the process of continuous changes. More and more experts and scholars are also using their efforts to develop new energy vehicles with artificial intelligence and big data. This new energy vehicle will have longer mileage and safer operation.

1.3. Contribution. The dual drive of the braking strategy based on each axis distribution between the regeneration braking force and mechanical braking force did not fully consider the front and rear axle regenerative braking force distribution has important influence on energy recovery, leading to poor recovery efficiency. So, this paper fully considers the important distribution influence of front and rear axle regenerative braking force on energy recovery. Based on the loss model of the front and rear motors, the distribution law of front and rear motor regenerative braking torques with the optimal system efficiency at the same speed was analyzed. The safety factors such as ECE regulations and ideal braking force distribution were used as constraints to study the motor efficiency. Finally, based on the big data platform, the driver's driving behavior is calculated. The motor driving force can be better matched with the driver's driving behavior, energy recovery efficiency, and battery parameters. Thus, more motor braking force distribution curve will fall into the high efficiency area, which ensures the maximum recovery efficiency of the motor. It provides a new way to prolong the driving mileage.

1.4. Structure of Text. This text was structured as follows: after mechanism analysis and model establishment of braking energy feedback in Section 2, Section 3 analyzes regenerative braking strategy of dual axle drive pure electric vehicle. Section 4 deals with simulation variation. Section 5 provides an example for the application of big data in energy recovery system. Section 6 proposes a conclusion. 


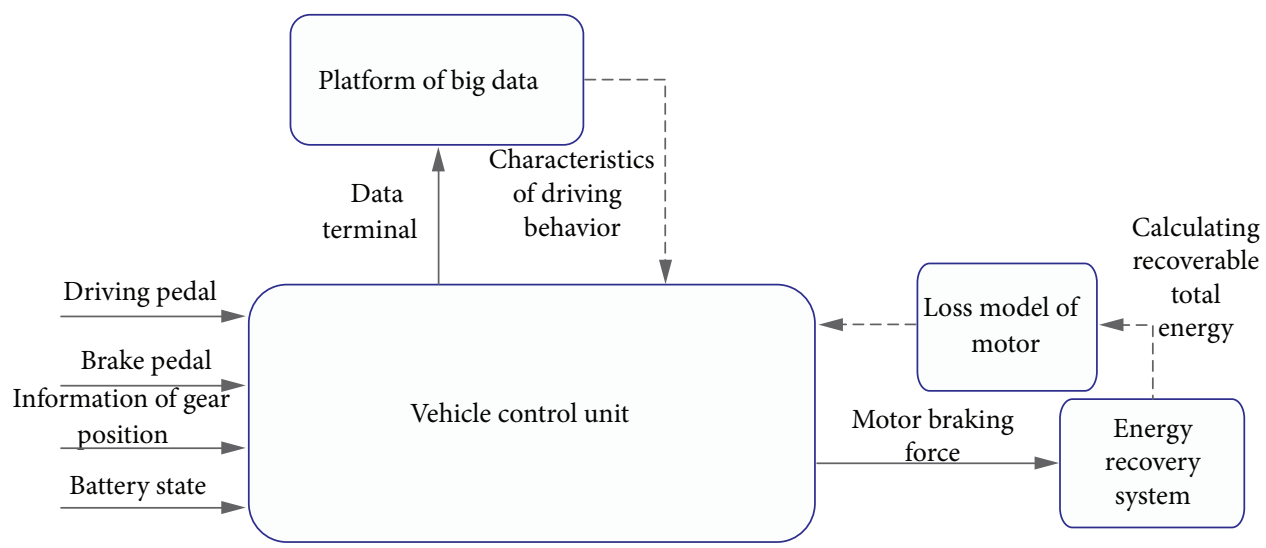

Figure 1: Energy recovery system based on big data and motor loss model.

\section{Mechanism Analysis and Complex System Model Establishment of Braking Energy Feedback}

This paper fully considers the efficiency of the power generation system for the dual motor system. Moreover, the effect of regenerative braking force distribution on energy recovery is fully considered. Finally, by analyzing the loss characteristics of the single motor, a loss model of dual motors is established.

2.1. Principle of Braking Energy Recovery. In the process of electric vehicle driving, the energy recovery model based on motor loss model and big data is shown in Figure 1.

As shown above, the whole control structure chart of large data computing platform combined with motor loss model can be seen. Driving information and vehicle information collected are analyzed by using the big data platform. The driving behavior characteristics are then sent to the vehicle controller. Vehicle controller also has the motor loss model to calculate the regenerative braking torque of the front and rear motors under the maximum loss energy recovery efficiency and calculate the compensation braking torque according to the driving behavior characteristics.

In the course of braking energy recovery, the braking force on the wheel was combined as

$$
F_{\mathrm{b}}=\frac{T_{\mathrm{e} 1} i_{1}}{\eta_{\mathrm{mec} 1} r}+\frac{T_{\mathrm{e} 2} i_{2}}{\eta_{\mathrm{mec} 2} r}+F_{\mathrm{bf} 1}+F_{\mathrm{bf} 2}+F_{\mathrm{w}}+F_{f} .
$$

The efficiency of dual motor is

$$
\eta_{\text {sys }}=\frac{\left(T_{\mathrm{e} 1}+T_{\mathrm{e} 2}\right) n-9500\left(P_{\mathrm{L} 1}+P_{\mathrm{L} 2}\right)}{T_{\mathrm{e}} n} .
$$

Regenerative braking power is

$$
P_{\text {reg }}=\frac{\left(T_{\mathrm{e} 1}+T_{\mathrm{e} 2}\right) n}{9550} \eta_{\text {sys }} \eta_{\mathrm{b}}
$$

The size of energy recovery is

$$
E=\int_{0}^{t_{0}} P_{\text {reg }} d t
$$

The input brake energy on the wheel is

$$
\Delta E_{k}=\frac{1}{2} m\left(v_{0}^{2}-v_{1}^{2}\right)
$$

The energy recovery efficiency is

$$
\eta=\frac{\int_{0}^{t_{0}} P_{\mathrm{reg}} d t}{\Delta E_{k}}
$$

where $v_{0}$ is initial speed of braking; $v_{1}$ is the end of the braking speed; $m$ is curb weight; $r$ is wheel radius; $i_{1}$ and $i_{2}$ are the front and rear shaft ratios; $F_{\mathrm{bf} 1}$ and $F_{\mathrm{bf} 2}$ are mechanical braking force of front wheel and rear wheel, respectively; $F_{f}$ is rolling resistance; $F_{\mathrm{w}}$ is wind-resistance; $\eta_{\text {mec } 1}$ and $\eta_{\text {mec } 2}$ are front and rear shaft drive system efficiency; $T_{\mathrm{e}}$ is regenerative braking torque at the shaft end of motor; $P_{\text {reg }}$ is the regenerative braking power; and $P_{\mathrm{L} 1}$ and $P_{\mathrm{L} 2}$ are the power losses in the energy feedback process of the front and rear motors, respectively. $\eta_{\mathrm{b}}$ is battery charging efficiency; $t_{0}$ is the end time of the regenerative braking; and $\eta_{\text {sys }}$ is a dual motor efficiency.

\subsection{Optimal Braking Energy Recovery Model with Dual-Axis} Drive. According to the above, improving the dual motor efficiency can realize the optimal energy recovery of dual axle drive pure electric vehicle for feedback braking. The efficiency of motor power generation is a function of motor torque and speed. According to the formula (6), the utilization efficiency of dual motors is related to the distribution of braking torque between the front and rear motors. In order to make the dual motors work as efficiently as possible in the 
high efficiency area, the optimal braking energy recovery model was established as follows:

$$
\begin{array}{ll}
\max \quad \eta_{s y s}=\frac{\omega_{1} T_{\mathrm{e} 1} / p_{1}+\omega_{2} T_{\mathrm{e} 2} / p_{2}-\left[P_{\mathrm{L} 1}\left(\omega_{1}, T_{\mathrm{e} 1}\right)+P_{\mathrm{L} 2}\left(\omega_{2}, T_{\mathrm{e} 2}\right)\right]}{\omega_{e 1} T_{\mathrm{e} 1}+\omega_{e 2} T_{\mathrm{e} 2}} \\
\text { s.t. }\left\{\begin{array}{l}
a=T_{\mathrm{e} 1} / T_{\mathrm{e}}, \\
T_{\mathrm{e} 2}=(1-a) T_{\mathrm{e}}, \\
0 \leq T_{\mathrm{e} 1} \leq T_{\mathrm{e} 1 \max }\left(n_{1}\right), 0 \leq T_{\mathrm{e} 2} \leq T_{\mathrm{e} 2 \max }\left(n_{2}\right), \\
0 \leq a \leq 1,
\end{array}\right.
\end{array}
$$

where $\omega_{1}$ and $\omega_{2}$ are the electrical angular velocities of the front and rear motors; $p_{1}$ and $p_{2}$ are the poles of the front and rear motors, respectively; $T_{\mathrm{e} 1}$ and $T_{\mathrm{e} 2}$ are braking torque of front and rear axle motor, respectively; $a$ is the torque distribution factor of the front axle motor; $T_{\mathrm{e} 1 \max (n 1)}$ is the maximum torque that the front motor can output at a speed of $n_{1} ; T_{\mathrm{e} 2 \max (n 2)}$ is the maximum torque that the rear motor can output at a speed of $n_{2}$; and $P_{\mathrm{L} 1}$ and $P_{\mathrm{L} 2}$ are the losses of front and rear motors, respectively, which is a function of motor speed and torque.

2.3. Numerical Simulation and Loss Model of Dual Motor System. In this paper, the relationship between the regenerative braking moment distribution and the regenerative braking recovery efficiency is mainly considered, but the transmission ratio is not the same. Therefore, (7) can be simplified as

$$
\eta_{\text {sys }}=\frac{\omega T_{\mathrm{e}} / p-P_{\mathrm{L}}}{\omega T_{\mathrm{e}}},
$$

where $\omega$ is the electrical angular speed of the motor; for the given speed and regenerative braking moment, the dual motor efficiency is only related to $P_{\mathrm{L}}$. The maximum value is obtained for the $\eta_{\text {sys }}$ motor loss minimum value of $P_{L}$. If the minimum $P_{\mathrm{L}}$ of the motor is desired, the input and output characteristics of the permanent magnet synchronous motor (PMSM) will be analyzed first. The input and output characteristics are usually described by the ratio $\eta$ of net output power $P_{\text {out }}$ to total input power $P_{\text {in }}$, namely,

$$
\eta=\frac{P_{\text {out }}\left(T_{\text {out }}, \omega\right)}{P_{\text {in }}\left(T_{\text {in }}, \omega\right)} .
$$

In practical application, the input-output system of convexity is widely used in PMSM. For this reason, this paper mainly studies convex systems, and nonconvex systems are not in the scope of study $[40,41]$.

Loss of permanent magnet synchronous motor mainly includes copper consumption, iron loss, friction loss, and stray loss. The stray loss is difficult to measure and control. However, because it usually occupies a smaller proportion of total loss, so it can generally be ignored. Friction loss power is generated by friction and winding losses. It is approximately linear with the speed of the motor [42, 43]. Therefore, only iron consumption and copper consumption are considered in this paper. The loss model of permanent magnet synchronous motor can be referred to [44, 45].

The voltage balance equation in steady state is

$$
\begin{aligned}
& u_{d}=R_{a} i_{d}-\omega \psi_{q}, \\
& u_{q}=R_{a} i_{q}+\omega \psi_{d} .
\end{aligned}
$$

$\psi_{d}$ and $\psi_{q}$ are the magnetic flux linkage of the stator $d$ axis and the $q$ axis, respectively,

$$
\begin{aligned}
& \psi_{d}=L_{d} i_{w d}+\psi_{f}, \\
& \psi_{q}=L_{q} i_{w q} .
\end{aligned}
$$

The flux torque equation is

$$
T_{\mathrm{e}}=\frac{3}{2} p\left(\psi_{d} i_{w q}-\psi_{q} i_{w d}\right)=\frac{3}{2} p\left[\psi_{f} i_{w q}+\left(L_{d}-L_{q}\right) i_{w d} i_{w q}\right]
$$

where $u_{d}$ and $u_{q}$ are stator $d$ axis and $q$ axis voltage; $i_{d}$ and $i_{q}$ are stator $d$ axis and $q$ axis current; $i_{d i}$ and $i_{q i}$ are stator equivalent $d$ and $q$ shaft loss currents; $i_{w d}$ and $i_{w q}$ are stator equivalent $d$ and $q$ shaft torque currents; $\psi_{f}$ is the flux generated by the permanent magnets; $R_{a}$ is stator winding phase resistance; $\omega$ is the angular speed of the rotor; $p$ is the pole count of the motor; $T_{\mathrm{e}}$ is the motor electromagnetic torque; and $L_{d}$ and $L_{q}$ are inductance of $d$ axis and $q$ axis, respectively.

In this paper, an example of an implicit PMSM is that the $d$ is generally the same as the $q$ axis (nonsalient pole). Therefore, the electromagnetic torque can be simplified as

$$
T_{\mathrm{e}}=\frac{3}{2} p \psi_{f} i_{w q}
$$

The copper loss power, the iron loss power, and the friction loss power of PMSM are, respectively,

$$
\begin{aligned}
P_{\mathrm{Cu}} & =\frac{3}{2} R_{a}\left(i_{d}^{2}+i_{q}^{2}\right)=\frac{3}{2} R_{a}\left[\left(i_{d i}+i_{w d}\right)^{2}+\left(i_{q i}+i_{w q}\right)^{2}\right] \\
& =\frac{3}{2}\left\{\left(-\frac{\omega L i_{w q}}{R_{c}}+i_{d i}\right)^{2}+\left[\frac{\omega\left(L i_{w d}+\psi_{f}\right)}{R_{c}}+i_{w q}\right]^{2}\right\} \\
P_{\mathrm{Fe}} & =\frac{3}{2} R_{c}\left(i_{i d}^{2}+i_{i q}^{2}\right) \\
& =\frac{3}{2} R_{c}\left\{\left(-\frac{\omega L i_{w q}}{R_{c}}\right)^{2}+\left[\frac{\omega\left(L i_{w d}+\psi_{f}\right)}{R_{c}}\right]^{2}\right\} \\
P_{\mathrm{f}} & =K_{f 1} \omega .
\end{aligned}
$$

There $K_{f 1}$ is the coefficient of the motor frictional resistance and can be obtained by bench test. 
Therefore, we can draw the total loss of single motor:

$$
\begin{aligned}
P_{\mathrm{L} 1}= & \frac{3}{2} R_{a}\left\{\left[\frac{2 T_{\mathrm{e}}}{3 p \psi_{f}}+\frac{\omega\left(\psi_{f}+L i_{w d}\right)}{R_{c}}\right]^{2}+\left[i_{w d}-\frac{2 \omega L T_{\mathrm{e}}}{3 R_{c} p \psi_{f} i_{w d}}\right]^{2}\right\} \\
& \left.\left.+\frac{3 \omega^{2}}{2} \frac{2 T_{\mathrm{e}} L}{R_{c}}\right)^{2}+\left(\psi_{f}+L i_{w d}\right)^{2}\right]+K_{f 1} \omega .
\end{aligned}
$$

Similarly, according to the formula (13) and (14), the loss power of dual motors can be obtained as follows:

$$
\begin{aligned}
P_{\mathrm{L}}= & \frac{3}{2} R_{a 1}\left[\left(\alpha A_{1}+B_{1}\right)^{2}+\left(C_{1}-D_{1}\right)^{2}\right] \\
& +\frac{3 \omega^{2}}{2 R_{c 1}}\left(\alpha^{2} E_{1}{ }^{2}+\frac{B_{1} R_{c 1}{ }^{2}}{\omega^{2}}\right)+K_{f 1} \omega \\
& +\frac{3}{2} R_{a 2}\left[\left(\alpha A_{2}+B_{2}\right)^{2}+\left(C_{2}-D_{2}\right)^{2}\right] \\
& +\frac{3 \omega^{2}}{2 R_{c 2}}\left(\alpha^{2} E_{2}{ }^{2}+\frac{B_{2} R_{c 2}{ }^{2}}{\omega^{2}}\right)+K_{f 2} \omega,
\end{aligned}
$$

where

$$
\begin{aligned}
& A_{1}=\frac{2 T_{\mathrm{e}}}{3 p \psi_{f 1}}, \\
& B_{1}=\frac{\omega\left(\psi_{f 1}+L_{1} i_{w d 1}\right)}{R_{c 1}}, \\
& C_{1}=i_{w d 1}, \\
& D_{1}=\frac{2 \omega L_{1} T_{\mathrm{e}}}{3 R_{c 1} p \psi_{f} i_{w d 1}}, \\
& E_{1}=\frac{2 T_{\mathrm{e}} L_{1}}{3 p \psi_{f 1}}, \\
& A_{2}=\frac{2 T_{\mathrm{e}}}{3 p \psi_{f 2}}, \\
& B_{2}=\frac{\omega\left(\psi_{f 2}+L_{2} i_{w d 2}\right)}{R_{c 2}}, \\
& C_{2}=i_{w d 2}, \\
& D_{2}=\frac{2 \omega L_{2} T_{\mathrm{e}}}{3 R_{c 2} p \psi_{f} i_{w d 2}}, \\
& E_{2}=\frac{2 T_{\mathrm{e}} L_{2}}{3 p \psi_{f 2}} .
\end{aligned}
$$

Then, by adjusting the flux setting value in real time, the PMSM is operated under the minimum loss control mode. At this point, the active component $i_{w d}$ of the $d$ axis current can be calculated by $d P_{\mathrm{L}} / d i_{w d}=0$, then

$$
i_{w d}=-\frac{\omega^{2} L \psi_{f}\left(R_{a}+R_{c}\right)}{\omega^{2} L^{2}\left(R_{a}+R_{c}\right)+R_{a} R_{c}^{2}} .
$$

In the formula, the $R_{c}$ is the motor equivalent iron resistance.

\section{Regenerative Braking Strategy and Calculation of Dual Axle Drive Pure Electric Vehicle}

The proportion of the front and rear braking force of a dual axle drive electric vehicle is the key factor affecting the braking safety. At the same time, the ratio of regenerative braking of front and rear motors is the key factor affecting the recovery of braking energy [46-48]. According to the relationship between the distribution ratio of the regenerative braking force and the motor efficiency, the braking force distribution strategy is optimized by using the ECE regulation and ideal braking force distribution as the constraints.

3.1. Regenerative Braking Torque Distribution Model Calculation of Dual Motor. Since the input and output of a single motor are convex, the input and output of the dual motor system must be convex, so there is a value that minimizes the system loss. For (15), the derivative is calculated. We can make $d_{P L} / d \alpha=0$, and then get the regenerative moment distribution coefficient of the whole system with the least loss. Then,

$$
\alpha=\frac{R_{\mathrm{a} 1}\left(C_{1} D_{1}-A_{1} B_{1}\right)+R_{a 2}\left(D_{2}^{2}-A_{2}^{2}-A_{2} B_{2}-C_{2} D_{2}\right)+\omega^{2} E_{2}^{2} / R C_{2}}{R_{a_{1}}\left(A_{1}^{2}+D_{1}^{2}\right)+\left(\omega^{2} E_{1}^{2} / R_{c 1}\right)+R_{a 2}\left(A_{2}^{2}+D_{2}^{2}\right)+\left(\omega^{2} E_{2}^{2} / R_{c 2}\right)} .
$$

3.2. Restraint Condition of Braking Force Distribution. First, we can refer to the brake safety regulations and the ideal braking force distribution curve, and then solve the safety area of vehicle braking force distribution. The braking safety region can be coupled with the maximum torque distribution model of motor efficiency. Finally, we can get a new regenerative braking control strategy.

3.2.1. Ideal Braking Force Distribution. The braking force distribution along the I curve, can well use the ground friction condition and guarantee vehicle braking direction stability [49]. Therefore, the distribution curve of the front and rear braking force is closer to the I curve, and the braking stability is better. At this time, the front wheel braking force and rear wheel braking force meet the following relations:

$$
F_{x b 2}=\frac{1}{2}\left[\frac{G}{h_{g}} \sqrt{b^{2}+\frac{4 h_{g} L}{G} F_{x b 1}}-\left(\frac{G b}{h_{g}}+2 F_{x b 1}\right)\right]
$$

where $F_{x b 1}$ is front wheel power; $F_{x b 2}$ is rear wheel power; $L$ is wheelbase; $h_{g}$ is the height of center of mass; $b$ is center of mass to rear axle; and $G$ is the gravity of vehicle.

3.2.2. ECE Braking Regulations. The ECE braking regulations provide for the car to ensure the stability of the braking direction and the braking efficiency [50-53]. For $z=0.2 \sim 0.8$, the adhesion factor should be satisfied with $\varphi \leq(z+0.07) / 0.85$ and close to the ideal $\varphi=z$ curve. In order to ensure the 


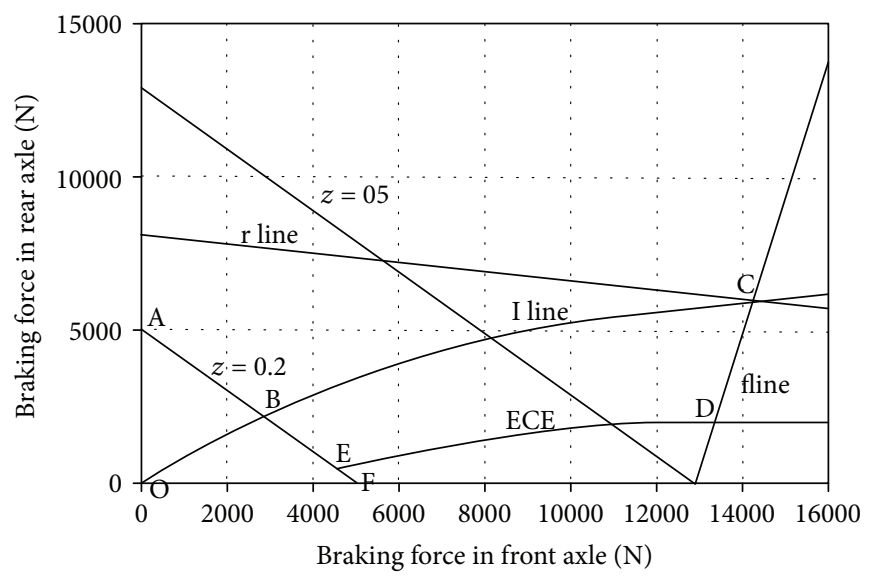

Figure 2: Brake safety zone.

braking efficiency, the equation of front and rear braking force is

$$
\begin{gathered}
\left(F_{x b 1}+F_{x b 2}\right)^{2}+G\left(0.07+\frac{b}{h_{g}}\right)\left(F_{x b 1}+F_{x b 2}\right) \\
-\frac{0.85 G L}{h_{g}} F_{x b 1}+0.07 \frac{G^{2} b}{h_{g}}=0 .
\end{gathered}
$$

The regulations do not provide $z<0.2$, front and rear wheel lock sequence, to sum up, the braking safety control curve as shown in Figure 2.

3.3. Braking Force Distribution Strategy Based on Optimization of Motor Efficiency. The braking force distribution satisfies the safety brake area constraint of Figure 2. When the motor speed is low (usually less than $500 \mathrm{r} / \mathrm{min}$ ) or the battery SOC is higher (SOC > 0.9), the regenerative braking system is switched off. When the braking force distribution point is in the OAF area, the braking force of the front and rear motor is optimally allocated according to the motor utilization efficiency. When the power distribution point is in the BCDE area, the power of the front and rear axles is distributed along the I curve; in the process of vehicle regenerative braking, if the braking force can not meet the braking force demand of the vehicle, the insufficient part is supplied by the hydraulic pressing power. The specific distribution process is as follows:

(1) When $z \leq 0.2$, the power distribution relationship between the front and rear wheels follows:

$$
\begin{aligned}
& F_{\text {reg } 1}=\alpha * \min \left(G z, \frac{2 i * T_{\mathrm{e} \max }(n)}{\eta_{\text {mec }} r}\right), \\
& F_{\text {reg2 }}=(1-\alpha) * \min \left(G z, \frac{2 i * T_{\mathrm{e} \max }(n)}{\eta_{\mathrm{mec}} r}\right), \\
& F_{\mathrm{bf} 1}=G z-F_{e 1}-F_{e 2}, \\
& F_{\mathrm{bf} 2}=0 .
\end{aligned}
$$

(2) When $0.2<z<0.5$, brake force is distributed along the I line, and the power distribution is as follows:

$$
\begin{aligned}
& F_{\text {reg1 }}=\min \left(F_{\mathrm{FI}}, \frac{T_{\mathrm{e} \max }(n) \cdot i}{r \cdot \eta_{\mathrm{mec}}}\right), \\
& F_{\mathrm{reg} 2}=\min \left(F_{\mathrm{RI}}, \frac{T_{\mathrm{e} \max }(n) \cdot i}{r \cdot \eta_{\mathrm{mec}}}\right), \\
& F_{\mathrm{bf} 1}=F_{\mathrm{FI}}-F_{e 1}, \\
& F_{\mathrm{bf} 2}=F_{\mathrm{RI}}-F_{e 2},
\end{aligned}
$$

where $F_{\mathrm{FI}}$ is the front axle power allocated by the I curve, the $F_{\mathrm{RI}}$ is the force of the rear axle which is allocated by the I curve, and the $i$ is the transmission ratio.

(3) When the brake strength $z \geq 0.5$, the vehicle is prone to the wheel lock. At this time, the main objective is to ensure the braking effect, and the braking system should be realized separately by the hydraulic braking system. Then, the wheel braking force is allocated along the ideal braking force distribution curve. At this time, the power distribution on the wheel is as follows:

$$
\begin{aligned}
& F_{\mathrm{bf} 1}=G z \frac{\left(b+z h_{g}\right)}{L}, \\
& F_{\mathrm{bf} 2}=G z \frac{\left(a-z h_{g}\right)}{L}, \\
& F_{\text {reg1 }}=0, \\
& F_{\text {reg2 }}=0 .
\end{aligned}
$$

\section{Verified through Numerical Simulation}

We built a simulation model with MATLAB/Simulink and CarSim. The evaluation criteria of braking energy recovery mentioned above are adopted, and then the effectiveness of the proposed regenerative braking energy recovery strategy is evaluated. This paper takes a certain type of dual drive pure 


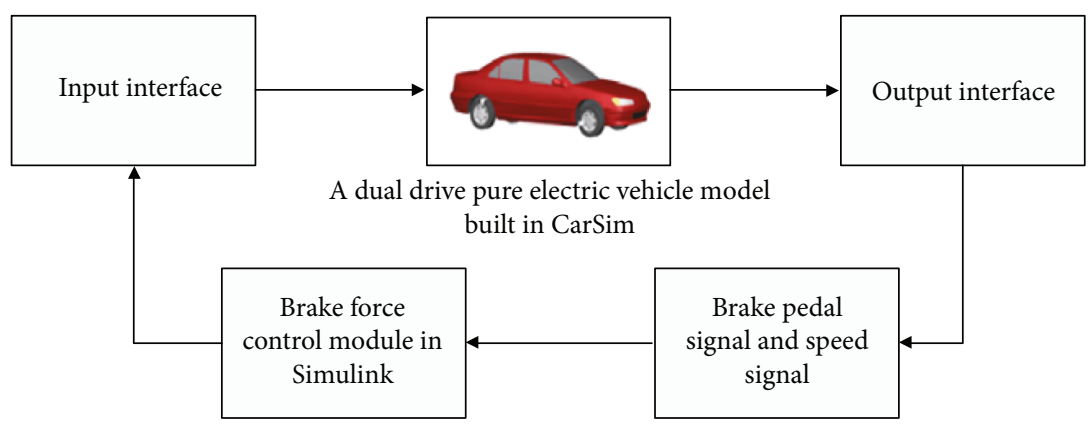

Figure 3: Mechanism diagram of simulation control combined with CarSim and Simulink.

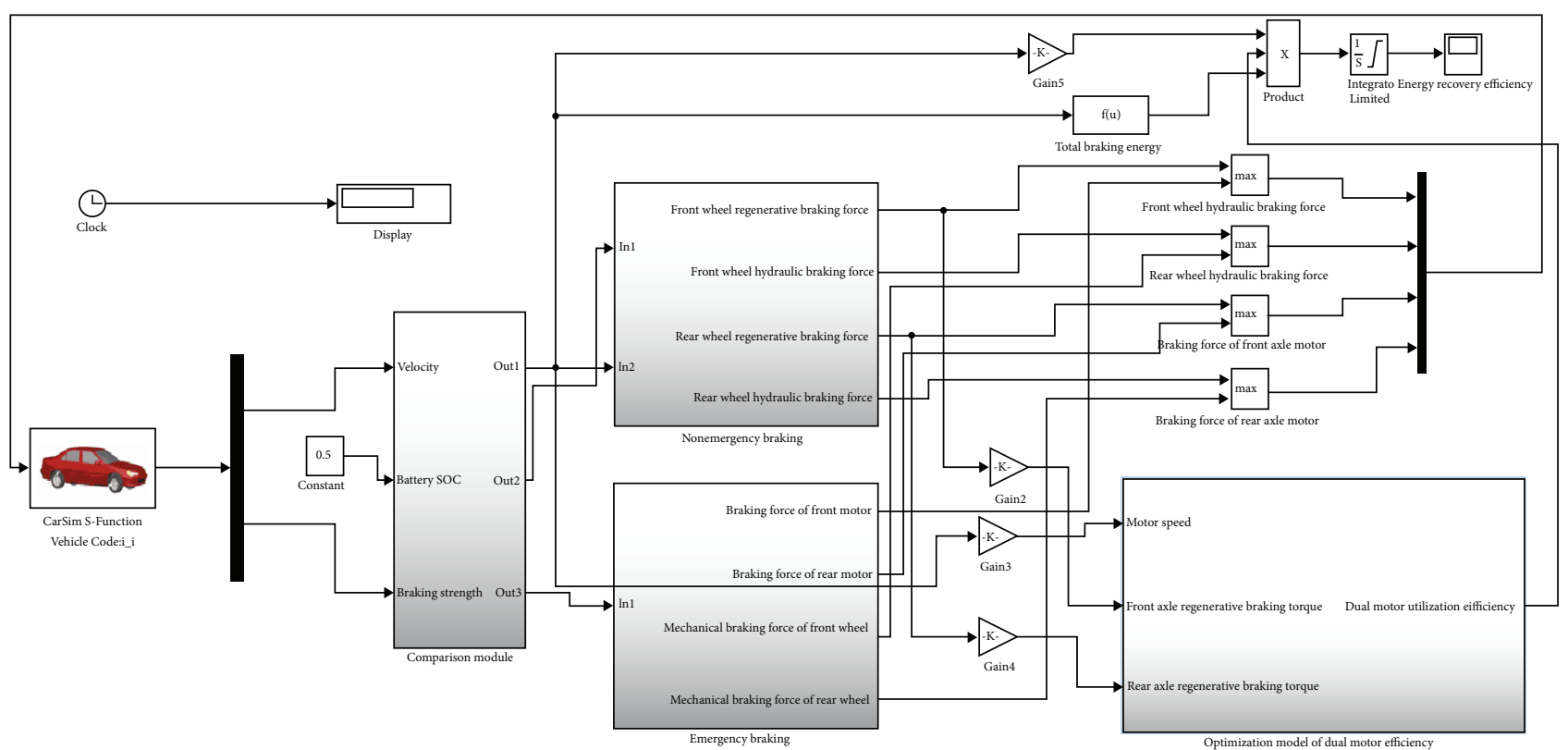

FIgURE 4: Regenerative braking simulation mode.

electric vehicle as an example. The strategy of this paper is compared with the braking force distribution strategy based on I line under cyclic condition. At the same time, it compares with the maximum braking energy recovery strategy of the front axle under cyclic condition. The initial SOC value of the battery is $50 \%$. Therefore, the effect of battery SOC on energy recovery efficiency can be ignored. In order to verify the control strategy, a vehicle dynamics model was built in CarSim. Then, we set up a motor, battery, and control strategy model in Simulink. Finally, a joint simulation model of CarSim and Simulink is established. The mechanism diagram of CarSim and Simulink's simulation control is shown in Figure 3. The specific joint simulation model is shown in Figure 4, and the simulation parameters are shown in Table 1. Because the time required for simulation in this paper is $1200 \mathrm{~s}$, at the same time, we want to ensure the efficiency and accuracy of the simulation results. Through continuous experiments, the final simulation step is $0.1 \mathrm{~s}$.

Since this paper only discusses the same situation of the front and rear motors, we can consider that the actual characteristics of the two motors are the same for the sake
TABLE 1: Example vehicle model parameters.

\begin{tabular}{lc}
\hline Parameters & Value \\
\hline Full load quality/kg & 2570 \\
Tire rolling radius/m & 0.358 \\
Wheelbase/m & 2.69 \\
Height of mass center/m & 0.619 \\
The distance between the center of mass and the & $1.287 / 1.403$ \\
front and rear axle/m & 45 \\
Peak power of front and rear motor/kw & 4 \\
Pole-pair number of the motor/pair & 2.875 \\
Stator resistance/ $\Omega$ & 108.23 \\
Equivalent iron loss resistance/ $\Omega$ & 8.5 \\
Inductance in $d$ axis/mH & 8.5 \\
Inductance in $q$ axis/mH & 0.048 \\
Permanent magnet flux linkage/Wb & 64 \\
Rated torque of front and rear motor/Nm & 180 \\
The peak torque of the front and rear motors/Nm & \\
\hline
\end{tabular}




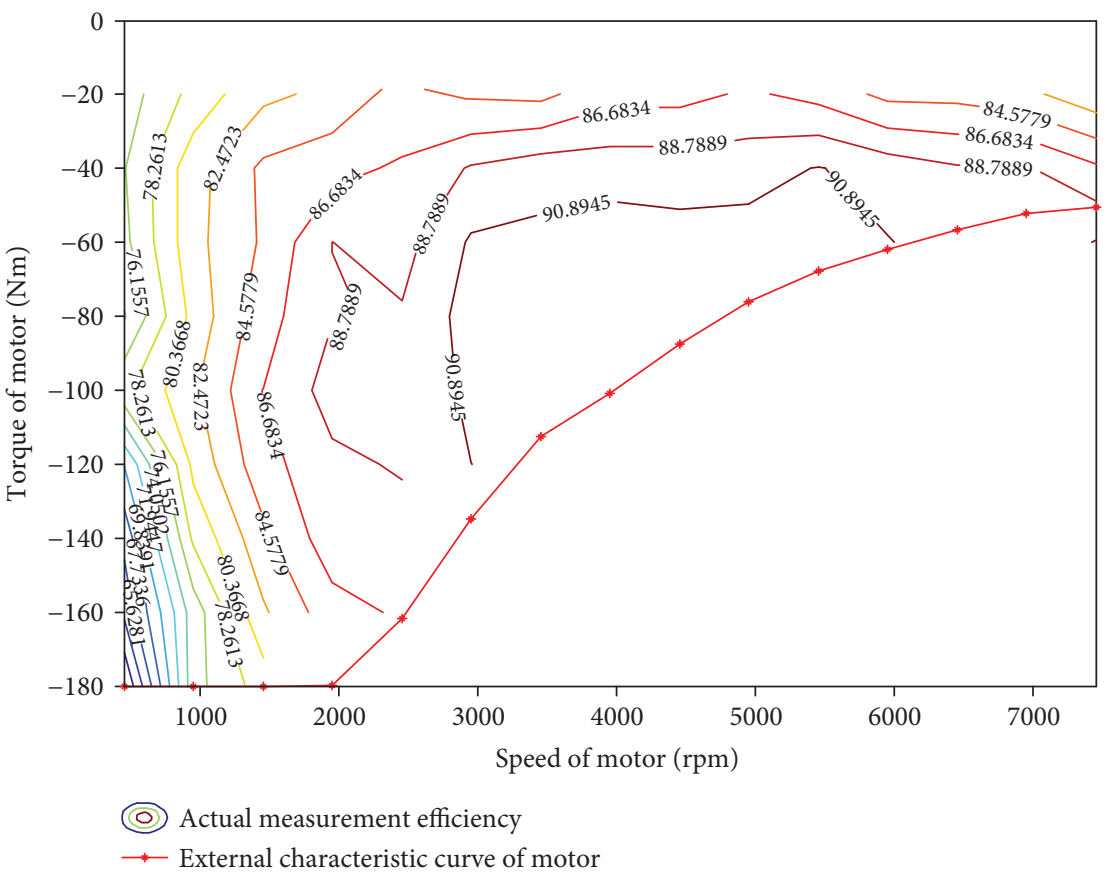

FIGURE 5: Measured map characteristic curve of motor.

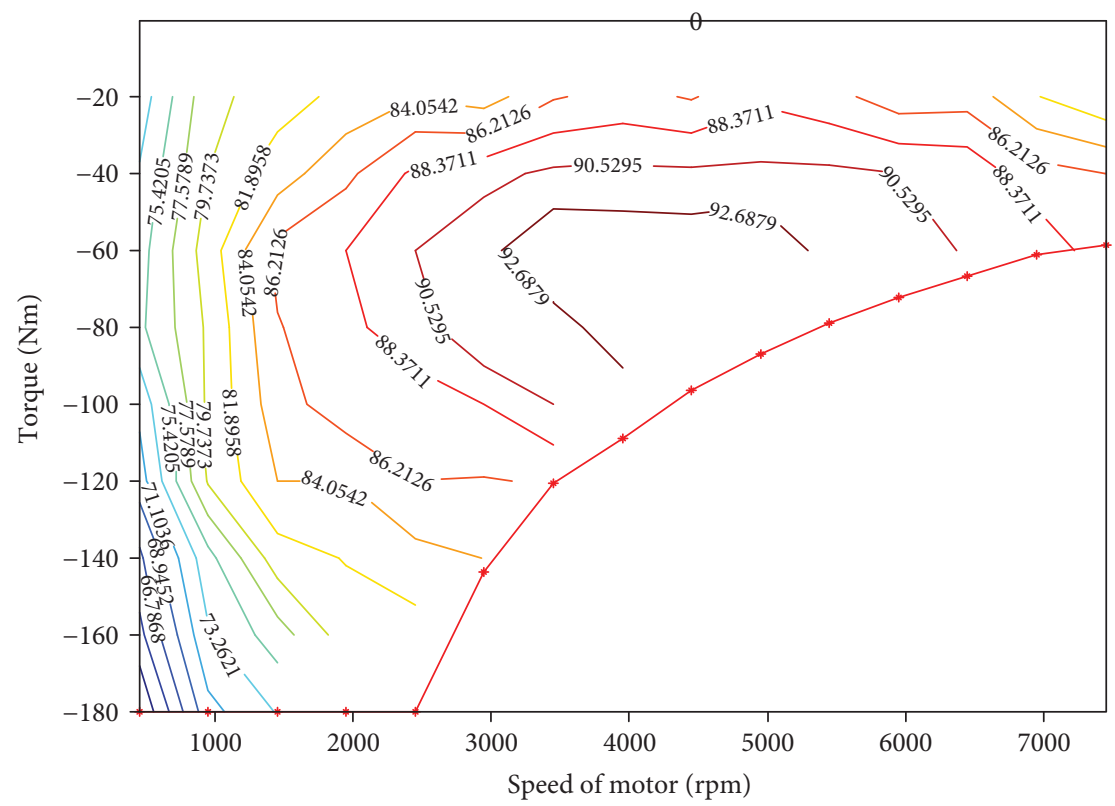

FIgURE 6: Motor prediction map characteristic curve.

of simple and convenient test. According to (8) and (19), the efficiency characteristics of the motor can be calculated. Figure 5 is the map curve obtained from dynamometer bench test. Figure 6 is the map curve obtained from theoretical calculation. By comparing the two diagrams, it can be seen that the coincidence degree between the two is better, and it can be concluded that the deduced dual motor loss model is accurate, and the model of the best distribution coefficient of the front and rear moment obtained by the derivative is correct.
We chose 5 different working points, and the distribution coefficient gradient was 0.01. Then, the electrical parameters of the front and rear motors are applied to 19. We can get the relationship between the distribution coefficient and the efficiency of the dual motor system, as shown in Figures 7 and 8. Figure 7 is the relationship between the braking torque distribution coefficient of the front and rear motors and the efficiency of the dual motor system when $1450 \mathrm{rpm}$ is used. Figure 8 is the relationship between the braking torque distribution coefficient of the front and rear 


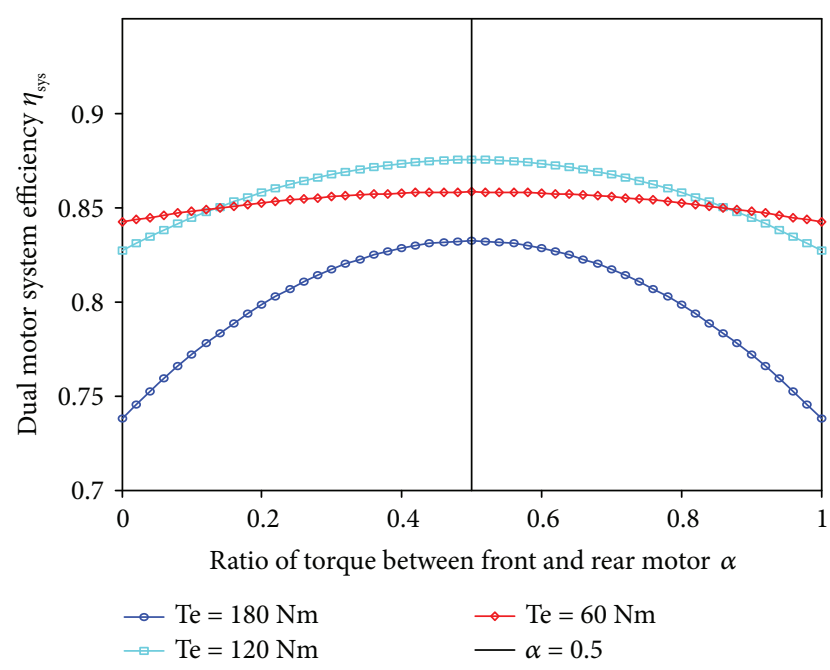

Figure 7: Schematic diagram of distribution at speed $1450 \mathrm{rpm}$.

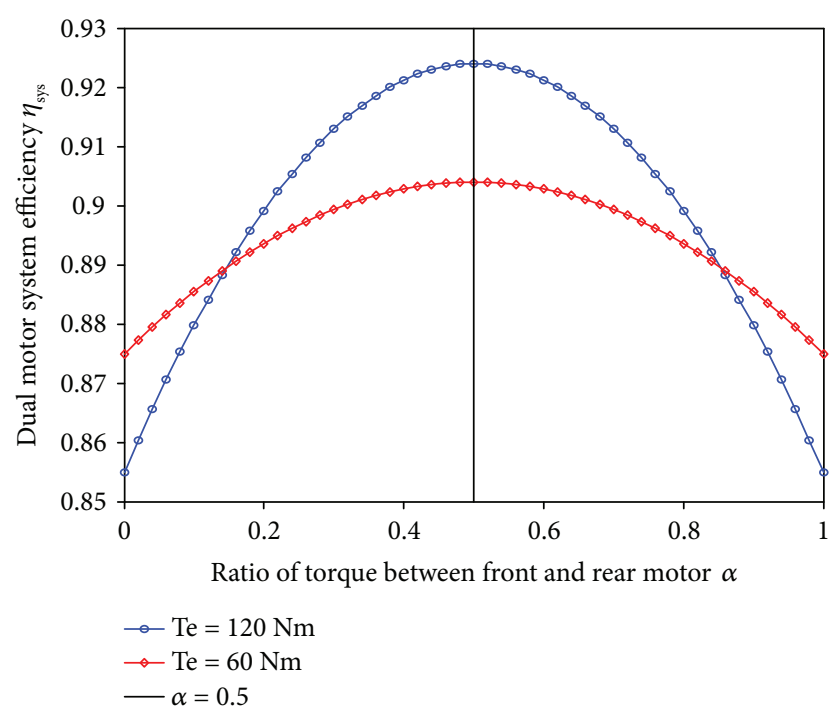

FIGURE 8: Schematic diagram of distribution at speed $3450 \mathrm{rpm}$.

motors and the efficiency of the dual motor system when $3450 \mathrm{rpm}$ is used.

Since the front and rear motor configurations are the same, the regenerative braking torque distribution factor $\alpha$ of the front and rear axles are valued between 0.5 and 1 . Calculate the optimum distribution coefficients of the front and rear motors corresponding to each operating point, as shown in Figure 9.

As shown in Figure 9, the optimal allocation coefficient for most of the working points is 0.5 . Only a small number of working points correspond to the best distribution coefficients between 0.5 and 0.545 , so they can be ignored. Therefore, the regenerative braking torque distribution coefficient of the front and rear motors is 0.5 . The best allocation coefficient we have determined is 0.5 , because when the motor is in a high torque state, the copper loss will be relatively large, resulting in low efficiency. When the motor is at low torque, if only one motor is working, the torque output of the other

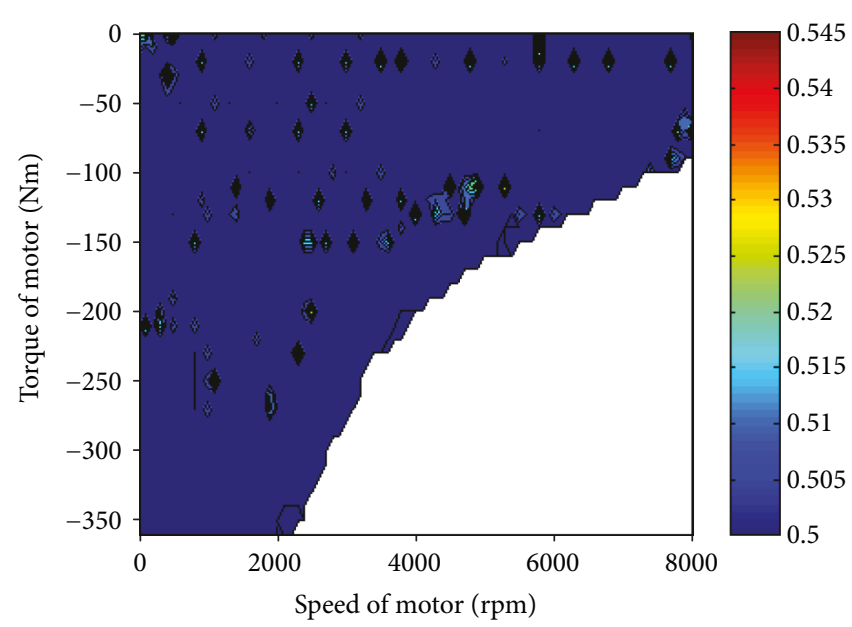

FIGURE 9: Optimal distribution coefficient of regenerative braking torque.

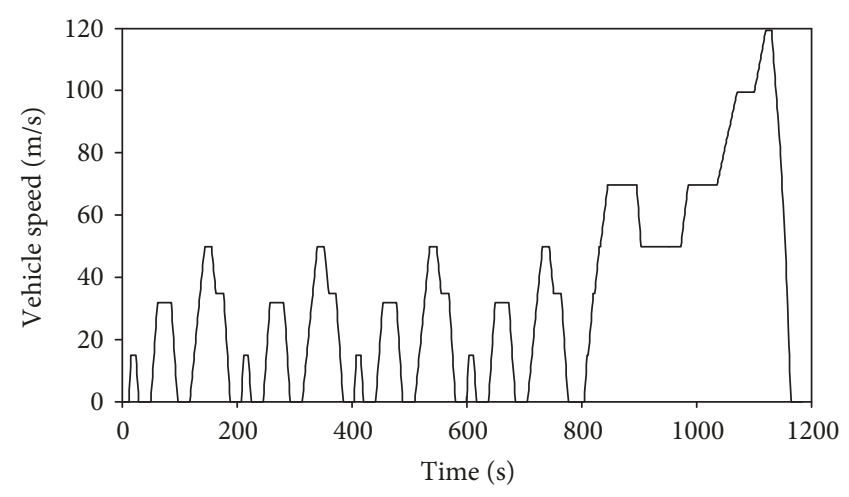

FIgURE 10: Speed diagram of NEDC condition based on data computation.

motor is 0 , but there will be no load loss. Therefore, the total loss of the system is still higher than the equal braking torque distribution. The torque distribution based on the map characteristic is neglecting the loss of the motor's no load. According to Figure 3, we can see that the value of $\alpha$ in 21 is 0.5 . Different energy recovery strategies are verified by selecting New European Driving Cycle (NEDC) cycle conditions. In order to simplify the description, strategy 1 is used to represent the braking force allocation strategy based on the optimization of the efficiency of motor utilization. Strategy 2 is used to represent the maximum regenerative dynamic strategy of the front axle, and strategy 3 is used to represent the braking force allocation strategy based on the I line. The speed of NEDC varies with time under cyclic condition, as shown in Figure 10.

The braking condition in the braking cycle is analyzed, and the deceleration distribution is obtained, as shown in Figure 11.

The motor loss energy of the three strategies under cyclic conditions is shown in Figure 12.

Under cyclic conditions, the motor efficiency of the three strategies is shown in Figure 13. 


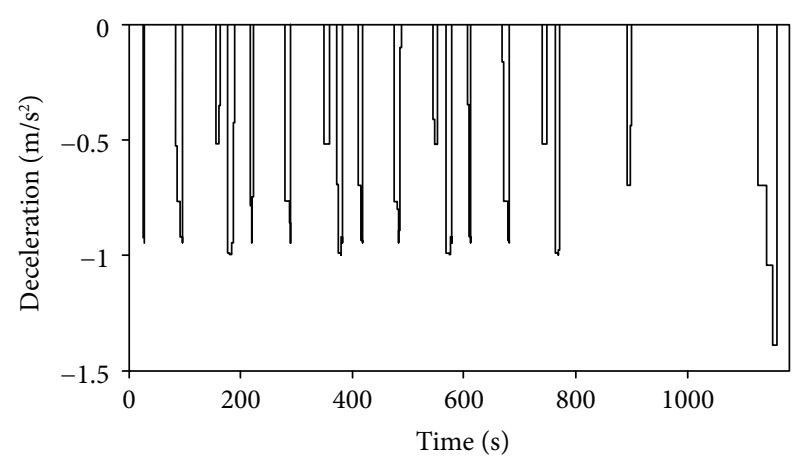

FIGURE 11: Braking deceleration diagram of NEDC condition.

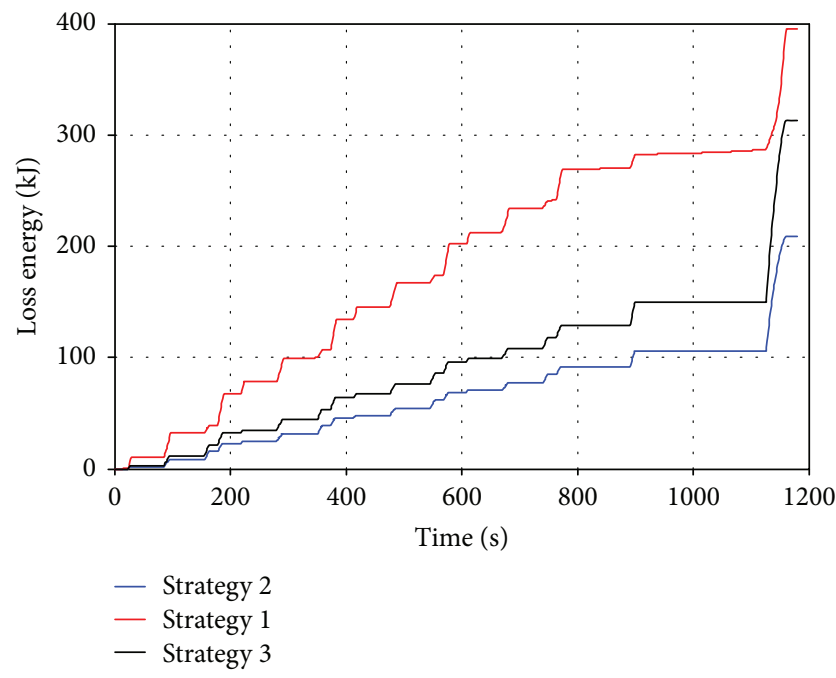

FIGURE 12: Energy loss of motor system under cyclic condition.

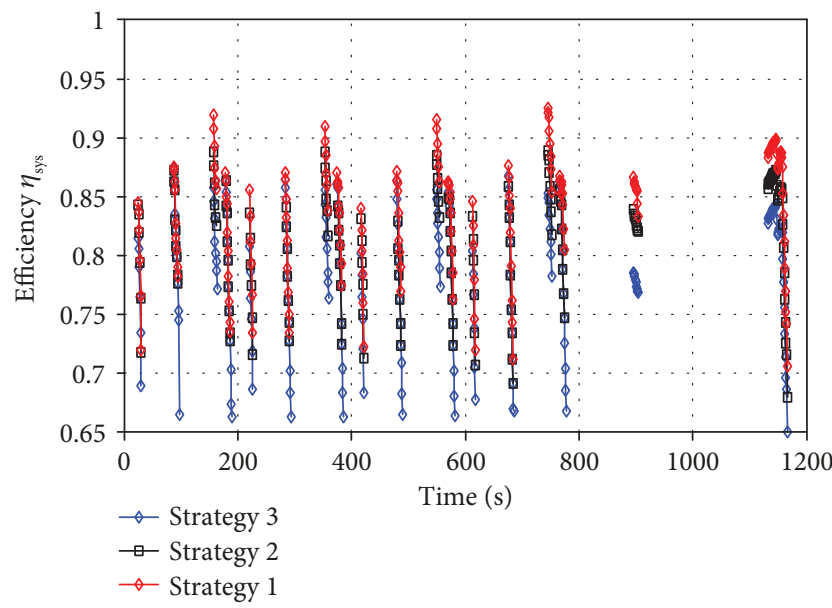

Figure 13: Utilization efficiency of dual motors under cyclic condition.

Under cyclic conditions, the energy recovery of the 3 strategies is shown in Table 2.

From Figures 12 and 13, the loss of the two-motor system under the regenerative braking control strategy is $208 \mathrm{~kJ}$, the
TABLE 2: Energy recovery under cyclic verification.

\begin{tabular}{lccc}
\hline Recovery strategy & $\triangle \mathrm{Ek} / \mathrm{kJ}$ & $\mathrm{E} / \mathrm{kJ}$ & $\eta / \%$ \\
\hline Strategy 1 & 3152.61 & 1885.27 & 79.06 \\
Strategy 2 & 3152.61 & 1675.90 & 70.28 \\
Strategy 3 & 3152.61 & 1817.31 & 76.21 \\
\hline
\end{tabular}

loss under the I line braking force distribution strategy is $313 \mathrm{~kJ}$, and the loss under the front axle maximum braking energy recovery strategy is $394 \mathrm{~kJ}$. The energy efficiency of the dual motor system is improved by $9.95 \%$ compared with the energy recovery strategy of the front axle. At the same time, the average utilization efficiency of the dual motor system is increased by $3.24 \%$ compared with the braking force distribution strategy based on the I line.

Table 2 shows how much energy the regenerative braking system can recover by adopting different control strategies in the NEDC cycle.

By adopting the braking strategy in this paper, the recovery energy reaches $1885.27 \mathrm{~kJ}$, and the energy recovery efficiency is $79.06 \%$. Compared with the other two strategies, the recovery efficiency is $8.78 \%$ and $2.85 \%$, respectively.

\section{Case: Braking Characteristics Based on Big Data Analysis}

For data obtained by a large number of statistical results, data processing must be done before the accuracy of subsequent modeling can be improved. In this paper, the following data indicators are used to deal with the driver's characteristic behavior data, typical are three kinds: "very small," "intermediate type," and "interval type."

Very small: for a very small data index $x$, the $x^{\prime}=$ $1 / x(x>0)$, or $x^{\prime}=M-x$.

Intermediate type: for an intermediate type index $x$, the

$$
x^{\prime}=\left\{\begin{array}{l}
\frac{2(x-m)}{M-m}, m \leq x \leq \frac{1}{2}(M+m) \\
\frac{2(M-x)}{M-m}, \frac{1}{2}(M+m) \leq x \leq M
\end{array}\right.
$$

Interval type: for an interval type index $x$, the

$$
x^{\prime}=\left\{\begin{array}{l}
1-\frac{a-x}{c}, x<a, \\
1, a \leq x \leq b, \\
1-\frac{x-b}{c}, x>b,
\end{array}\right.
$$

in which $[\mathrm{a}, \mathrm{b}]$ is the best stable interval, $c=\max \{a-m$, $M-b\}, M$, and $m$ are the maximum and minimum values of $x$, respectively.

Based on the above three data processing methods, this paper selects a large number of driver behavior data to derive statistical rules.

The main purpose of this paper is to use big data platform to maximize energy recovery. The main purpose is to improve the endurance of electric vehicles. At present, the 


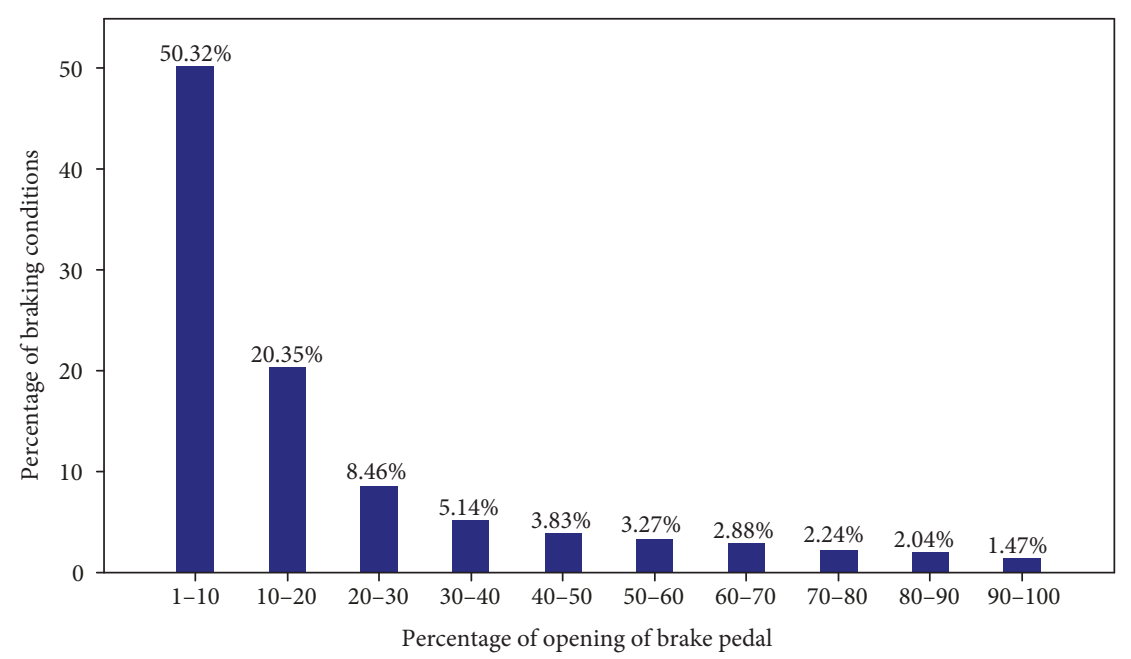

FIGURE 14: Statistical schematic of brake pedal opening.

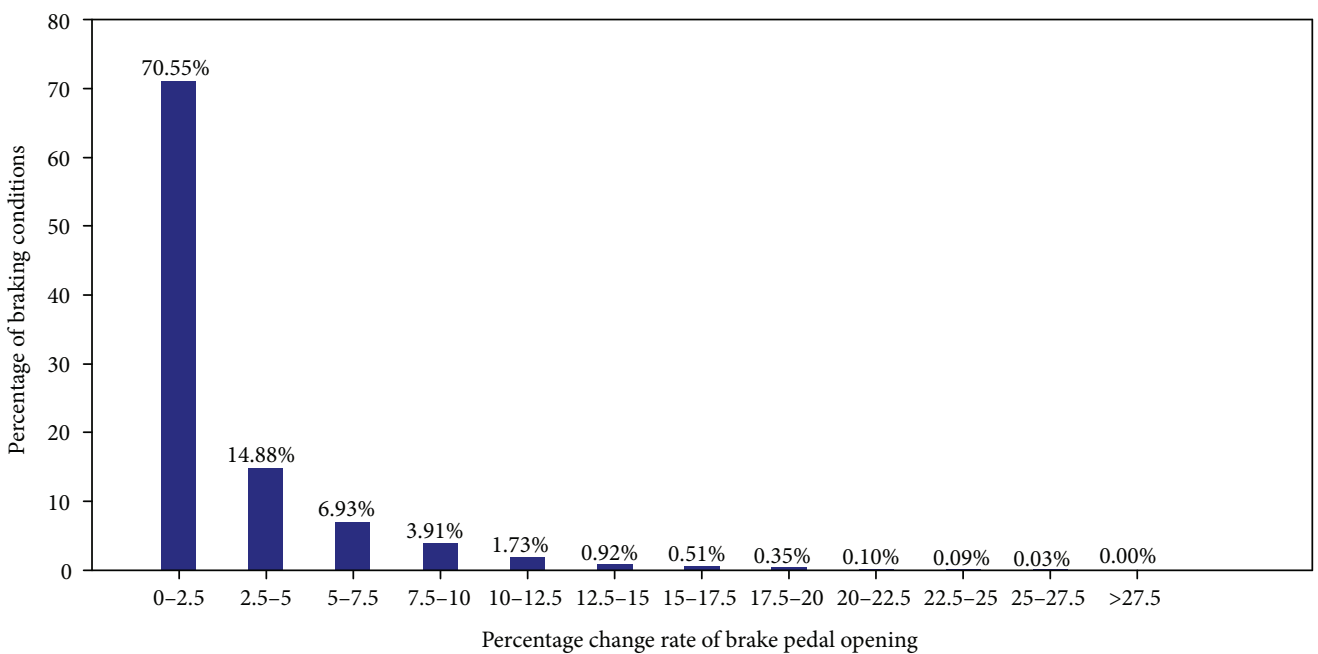

FIGURE 15: The change rate schematic diagram of brake pedal opening.

energy recovery of electric vehicles is usually carried out in the process of braking or sliding, but there are also problems such as low energy recovery efficiency, vehicle comfort, and battery safety. The existing braking energy recovery system does not take into account the driver's driving behavior and driving habits. This text mainly analyzes how to calculate the optimal efficiency of energy recovery by big data calculation. Figures 14, 15, and 16 are collected by a large number of drivers who have been driving for a long time. This paper mainly considers the braking characteristics of drivers during long-term driving.

Figures 14 and 15 are the results of the analysis of drivers' driving behavior obtained by statistics of thousands or higher orders. It is mainly the driver who gets the common characteristics of the depth and speed of the pedaling pedal under normal driving conditions. Figure 14 shows that the driver's daily brake pedal opening is below $50 \%$, accounting for $90 \%$ of the braking condition. Figure 15 shows that the brake pedal change rate of $25 \% / \mathrm{s}$ is less than $71 \%$. Therefore, from the above two big data statistics, the result is that when the pedal opening is above $50 \%$, or the brake pedal change rate

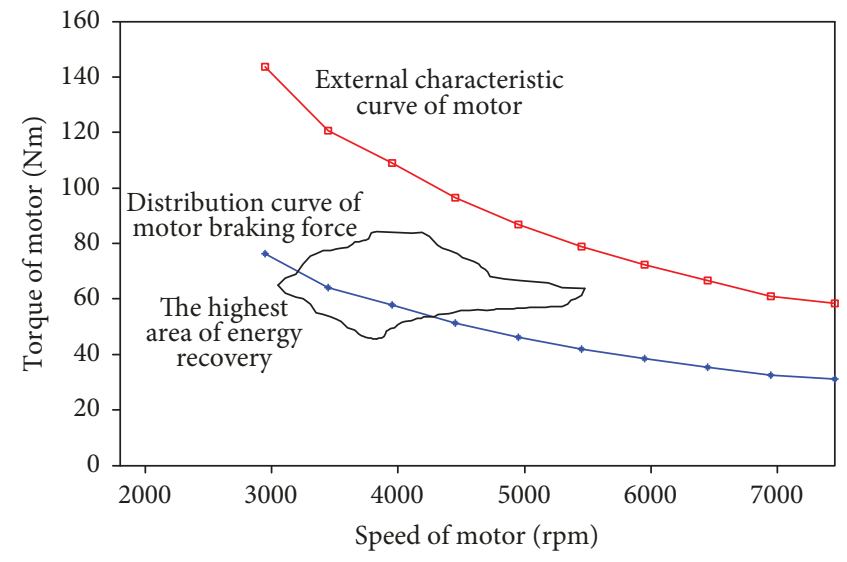

FIgURE 16: Maximum area distribution map of energy recovery efficiency.

is $25 \% / \mathrm{s}$, the above is the beginning of energy recovery. This conclusion can complement the above model of motor loss energy recovery. 
Figure 16 is based on the test data obtained from the permanent magnet synchronous motor used in this paper for many times on the dynamometer bench. Then draw the maximum area diagram of the energy recovery of the motor under braking condition. The optimal efficiency interval analyzed by a large number of data can be used for motor regenerative braking. By controlling it in the most efficient recovery area, the maximum energy recovery of electric vehicles can be achieved.

5.1. Summary. The driver's driving behavior based on the big data platform can better match the motor braking force to the driver's driving behavior, the energy recovery efficiency, and the battery parameters. Therefore, it makes more motor braking force distribution curve fall in the high efficiency area, so as to ensure the maximum recovery efficiency. At the same time, it also takes into account battery safety and driver's driving experience to ensure the safety and comfort of vehicle braking process.

\section{Conclusions}

This paper focuses on the optimization of motor power generation efficiency in the dual axle drive pure electric vehicle during the feedback braking process. Based on the loss model of the front and rear motors, we propose an analytical method to obtain the optimal braking torque distribution for dual motors. On the basis of this method, the safety factors such as ECE regulations and ideal braking force distribution are taken as constraints. We have developed a new energy recovery strategy for dual drive pure electric vehicles. Finally, a regenerative braking model is established and verified under cyclic condition.

Compared with the strategy based on the I line brake force distribution and the maximum brake force distribution strategy on the front axle, the strategy developed in this paper significantly reduces the total loss of the motor. It can be recovered even under the requirements of braking safety and stability. Through the driver's driving behavior obtained by the big data platform, this paper analyzes how the motor braking force matches the driver's driving behavior characteristics and energy recovery efficiency and provides a reference for the follow-up system of electric vehicle braking energy recovery based on big data calculation. The results of this paper provide a reference to the braking capacity feedback intelligent control for future new energy vehicles based on big data analysis [54-57].

With the development of information technology, the future big data will be more widely applied to the development of electric vehicles. According to the data generated by vehicles on the road, the data generated by vehicles are collected and analyzed by big data technology. This will provide a reliable basis for the development of electric vehicle energy recovery control strategy and power battery management system.

On the basis of large data analysis, the braking torque distribution model based on motor loss model is established in this paper. The simulation is used to verify the effectiveness of the proposed strategy. Next step is to embed the strategy into real vehicles for testing. Real vehicle verification mainly verifies the same condition of the motor before and after. At the same time, it is also necessary to verify whether the strategy is valid if the two axis motors are different.

\section{Data Availability}

The data used to support the findings of this study are available from the corresponding author upon request, or other authors.

\section{Conflicts of Interest}

The authors declare that there is no conflict of interests regarding the publication of this article.

\section{Acknowledgments}

This work was supported by the National Natural Science Foundation of China (Grant nos. 51575205 and 51775565), and the Guangdong Provincial Science and Technology Department (Grant no. 2016B010118001).

\section{References}

[1] M. Canale, L. Fagiano, A. Ferrara, and C. Vecchio, "Vehicle yaw control via second-order sliding-mode technique," IEEE Transactions on Industrial Electronics, vol. 55, no. 11, pp. 3908-3916, 2008.

[2] R. Maia, M. Silva, R. Araújo, and U. Nunes, "Electrical vehicle modeling: a fuzzy logic model for regenerative braking," Expert Systems with Applications, vol. 42, no. 22, pp. 85048519, 2015.

[3] L. Wang, M. Cai, H. Zhang, F. Alsaadi, and L. Chen, "Active fault-tolerant control for wind turbine with simultaneous actuator and sensor faults," Complexity, vol. 2017, Article ID 6164841, 11 pages, 2017.

[4] M. Ortuzar, J. Moreno, and J. Dixon, "Ultracapacitor-based auxiliary energy system for an electric vehicle: implementation and evaluation," IEEE Transactions on Industrial Electronics, vol. 54, no. 4, pp. 2147-2156, 2007.

[5] J. Han, Y. Park, and Y. Park, "Cooperative regenerative braking control for front-wheel-drive hybrid electric vehicle based on adaptive regenerative brake torque optimization using under-steer index," International Journal of Automotive Technology, vol. 15, no. 6, pp. 989-1000, 2014.

[6] L. Wang, S. Lin, J. Yang et al., "Dynamic traffic congestion simulation and dissipation control based on traffic flow theory model and neural network data calibration algorithm," Complexity, vol. 2017, Article ID 5067145, 11 pages, 2017.

[7] A. Gonzalez-Gil, R. Palacin, and P. Batty, "Sustainable urban rail systems: Strategies and technologies for optimal management of regenerative braking energy," Energy Conversion and Management, vol. 75, pp. 374-388, 2013.

[8] M.-Y. Zhou, H. Liao, W.-M. Xiong, X.-Y. Wu, and Z.-W. Wei, "Connecting patterns inspire link prediction in complex networks," Complexity, vol. 2017, Article ID 8581365, 12 pages, 2017.

[9] J. Ko, S. Ko, H. Son, B. Yoo, J. Cheon, and H. Kim, “Development of brake system and regenerative braking cooperative control algorithm for automatic-transmission-based hybrid 
electric vehicles," IEEE Transactions on Vehicular Technology, vol. 64, no. 2, pp. 431-440, 2015.

[10] M. Deissenroth, M. Klein, K. Nienhaus, and M. Reeg, “Assessing the plurality of actors and policy interactions: agentbased modelling of renewable energy market integration," Complexity, vol. 2017, Article ID 7494313, 24 pages, 2017.

[11] R. Ramakrishnan, S. S. Hiremath, and M. Singaperumal, "Theoretical investigations on the effect of system parameters in series hydraulic hybrid system with hydrostatic regenerative braking," Journal of Mechanical Science and Technology, vol. 26, no. 5, pp. 1321-1331, 2012.

[12] X. Li, J. Lai, and R. Tang, "A hybrid constraints handling strategy for multiconstrained multiobjective optimization problem of microgrid economical/environmental dispatch," Complexity, vol. 2017, Article ID 6249432, 12 pages, 2017.

[13] Y. H. Ki, K. J. Lee, J. S. Cheon, and H. S. Ahn, "Design and implementation of a new clamping force estimator in electro-mechanical brake systems," International Journal of Automotive Technology, vol. 14, no. 5, pp. 739-745, 2013.

[14] J. Wang, C. Zhang, H. Zhu, X. Huang, and L. Zhang, "RBF nonsmooth control method for vibration of building structure with actuator failure," Complexity, vol. 2017, Article ID 2513815, 7 pages, 2017.

[15] G. M. Fetene, S. Kaplan, S. L. Mabit, A. F. Jensen, and C. G. Prato, "Harnessing big data for estimating the energy consumption and driving range of electric vehicles," Transportation Research Part D: Transport and Environment, vol. 54, pp. 1-11, 2017.

[16] X. Diao, Y. Jin, L. Ma, S. Ding, and H. Jiang, "Composite active front steering controller design for vehicle system," IEEE Access, vol. 5, pp. 6697-6706, 2017.

[17] E. Webborn and R. S. MacKay, "A stability analysis of thermostatically controlled loads for power system frequency control," Complexity, vol. 2017, Article ID 5031505, 26 pages, 2017.

[18] C. Lv, J. Zhang, Y. Li, and Y. Yuan, "Mechanism analysis and evaluation methodology of regenerative braking contribution to energy efficiency improvement of electrified vehicles," Energy Conversion and Management, vol. 92, pp. 469$482,2015$.

[19] Q. H. Dang and M. Yoo, "Handover procedure and algorithm in vehicle to infrastructure visible light communication," IEEE Access, vol. 5, pp. 26466-26475, 2017.

[20] K. Liu, J. Wang, T. Yamamoto, and T. Morikawa, "Exploring the interactive effects of ambient temperature and vehicle auxiliary loads on electric vehicle energy consumption," Applied Energy, vol. 231, 2017.

[21] D. Wang, X. Ma, D. Ma, and S. Jin, "A novel speed-density relationship model based on the energy conservation concept," IEEE Transactions on Intelligent Transportation Systems, vol. 18, no. 5, pp. 1179-1189, 2017.

[22] J. Bacik, F. Durovsky, M. Biros, K. Kyslan, D. Perdukova, and S. Padmanaban, "Pathfinder-development of automated guided vehicle for hospital logistics," IEEE Access, vol. 5, pp. 26892-26900, 2017.

[23] G. Tian, M. Zhou, and P. Li, "Disassembly sequence planning considering fuzzy component quality and varying operational cost," IEEE Transactions on Automation Science and Engineering, vol. 15, no. 2, pp. 748-760, 2018.

[24] G. Tian, H. Zhang, Y. Feng et al., "Operation patterns analysis of automotive components remanufacturing industry development in China," Journal of Cleaner Production, vol. 164, pp. 1363-1375, 2017.

[25] Y. Li, R. Cui, Z. Li, and D. Xu, "Neural network approximation-based near-optimal motion planning with kinodynamic constraints using RRT," IEEE Transactions on Industrial Electronics, vol. 65, no. 11, pp. 8718-8729, 2018.

[26] X. Xu, H. Wang, N. Zhang, Z. Liu, and X. Wang, "Review of the fault mechanism and diagnostic techniques for the range extender hybrid electric vehicle," IEEE Access, vol. 5, pp. 14234-14244, 2017.

[27] H. Xiao, R. Cui, and D. Xu, "A sampling-based Bayesian approach for cooperative multi-agent online search with resource constraints," IEEE Transactions on Cybernetics, vol. 48, no. 6, pp. 1773-1785, 2018.

[28] R. Cui, L. Chen, C. Yang, and M. Chen, "Extended state observer-based integral sliding mode control for an underwater robot with unknown disturbances and uncertain nonlinearities," IEEE Transactions on Industrial Electronics, vol. 64, no. 8, pp. 6785-6795, 2017.

[29] M. Mao, Y. Yue, and L. Chang, "Multi-time scale forecast for schedulable capacity of electric vehicle fleets using big data analysis," in 2016 IEEE 7th International Symposium on Power Electronics for Distributed Generation Systems (PEDG), pp. 1-7, Vancouver, BC, Canada, June 2016.

[30] L. Yang, B. Wang, R. Zhang, H. Zhou, and R. Wang, "Analysis on Location Accuracy for the Binocular Stereo Vision System," IEEE Photonics Journal, vol. 10, no. 1, pp. 1-16, 2018.

[31] N. Urasaki, T. Senjyu, K. Uezato, and T. Funabashi, “An adaptive dead-time compensation strategy for voltage source inverter fed motor drives," IEEE Transactions on Power Electronics, vol. 20, no. 5, pp. 1150-1160, 2005.

[32] C. Bi, Y. Yuan, R. Zhang, Y. Xiang, Y. Wang, and J. Zhang, "A dynamic mode decomposition based edge detection method for art images," IEEE Photonics Journal, vol. 9, no. 6, pp. 1-13, 2017.

[33] C. Bi, Y. Yuan, J. W. Zhang et al., "Dynamic mode decomposition based video shot detection," IEEE Access, vol. 6, pp. 21397-21407, 2018.

[34] A. Sorniotti, T. Holdstock, M. Everitt et al., "A novel clutchless multiple-speed transmission for electric axles," International Journal of Powertrains, vol. 2, no. 2/3, p. 103, 2013.

[35] B. Yu, Z. Z. Yang, and J. X. Xie, "A parallel improved ant colony optimization for multi-depot vehicle routing problem," Journal of the Operational Research Society, vol. 62, no. 1, pp. 183-188, 2011.

[36] B. Yu, Z. Z. Yang, P. H. Jin, S. H. Wu, and B. Z. Yao, “Transit route network design-maximizing direct and transfer demand density," Transportation Research Part C, vol. 22, no. 5, pp. 58-75, 2012.

[37] M. H. B. Peeie, H. Ogino, and Y. Oshinoya, "Skid control of a small electric vehicle with two in-wheel motors: simulation model of ABS and regenerative brake control," International Journal of Crashworthiness, vol. 21, no. 5, pp. 396-406, 2016.

[38] M. I. Ghiasi, M. A. Golkar, and A. Hajizadeh, "Lyapunov based-distributed fuzzy-sliding mode control for building integrated-DC microgrid with plug-in electric vehicle," IEEE Access, vol. 5, pp. 7746-7752, 2017.

[39] C.-H. Lee and C.-H. Wu, "Collecting and mining big data for electric vehicle systems using battery modeling data," in 2015 12th International Conference on Information 
Technology - New Generations, pp. 626-631, Las Vegas, NV, USA, April 2015.

[40] Q. Guo, C. Zhang, L. Li, D. Gerada, J. Zhang, and M. Wang, "Design and implementation of a loss optimization control for electric vehicle in-wheel permanent-magnet synchronous motor direct drive system," Applied Energy, vol. 204, pp. 1317-1332, 2017.

[41] S. Gunther, S. Ulbrich, and W. Hofmann, "Driving cycle-based design optimization of interior permanent magnet synchronous motor drives for electric vehicle application," in 2014 International Symposium on Power Electronics, Electrical Drives, Automation and Motion, pp. 25-30, Ischia, Italy, June 2014.

[42] Y. Xiang, H. Zhou, W. Yang, J. Liu, Y. Niu, and J. Guo, "Scale evolution of electric vehicles: a system dynamics approach," IEEE Access, vol. 5, pp. 8859-8868, 2017.

[43] X. Qiu, W. Huang, F. Bu, and J. Yang, "Efficiency optimization of IPMSM direct torque control system used in electric vehicles," Transactions of China Electrotechnical Society, vol. 30, no. 22, pp. 43-45, 2015.

[44] M. Caruso, A. O. D. Tommaso, R. Miceli et al., "Characterization of the parameters of interior permanent magent synchronous motors for a loss model algorithm," Measurement, vol. 106, pp. 196-202, 2017.

[45] R. A. Rahman, G. Kendall, R. Ramli, Z. Jamari, and K. R. Ku-Mahamud, "Shrimp feed formulation via evolutionary algorithm with power heuristics for handling constraints," Complexity, vol. 2017, Article ID 7053710, 12 pages, 2017.

[46] K. Suthamno and S. Sujitjom, "Modellling of permanent magnet synchronous motor incorporating core-loss," Research Journal of Applied Sciences, Engineering and Technology, vol. 4, no. 17, pp. 2846-2853, 2012.

[47] N. Nakao and A. Kan, "Current optimization strategy for surface permanent magnet synchronous motor drives based on a rigorous mathematical model," in 2013 International Electric Machines \& Drives Conference, pp. 1188-1195, Chicago, IL, USA, May 2013.

[48] K. Han, S. B. Choi, J. Lee, D. Hyun, and J. Lee, “Accurate brake torque estimation with adaptive uncertainty compensation using a brake force distribution characteristic," IEEE Transactions on Vehicular Technology, vol. 66, no. 12, pp. 1083010840, 2017.

[49] C. Song, J. Wang, and L. Jin, "Study on the composite ABS control of vehicles with four electric wheels," Journal of Computers, vol. 6, no. 3, 2011.

[50] R. H. Zhang, Y. B. Ma, F. You, T. Peng, Z. C. He, and K. N. Li, "Exploring to direct the reaction pathway for hydrogenation of levulinic acid into $\gamma$-valerolactone for future clean-energy vehicles over a magnetic $\mathrm{Cu}-\mathrm{Ni}$ catalyst," International Journal of Hydrogen Energy, vol. 42, no. 40, pp. 25185-25194, 2017.

[51] R. H. Zhang, Z. C. He, H. W. Wang, F. You, and K. N. Li, "Study on self-tuning tyre friction control for developing main-servo loop integrated chassis control system," IEEE Access, vol. 5, pp. 6649-6660, 2017.

[52] R. Zhang, K. Li, F. Yu, Z. He, and Z. Yu, "Novel electronic braking system design for EVS based on constrained nonlinear hierarchical control," International Journal of Automotive Technology, vol. 18, no. 4, pp. 707-718, 2017.

[53] J. J. Kim, J. Hong, and S. J. Lee, "Bio-inspired cab-roof fairing of heavy vehicles for enhancing drag reduction and driving stability," International Journal of Mechanical Sciences, vol. 131-132, pp. 868-879, 2017.

[54] M. Shafiq, M. A. Shafiq, and H. A. Yousef, "Stability and convergence analysis of direct adaptive inverse control," Complexity, vol. 2017, Article ID 7834358, 12 pages, 2017.

[55] R. Zhang, J. Wu, L. Huang, and F. You, "Study of bicycle movements in conflicts at mixed traffic unsignalized intersections," IEEE Access, vol. 5, pp. 10108-10117, 2017.

[56] D. Ma, X. Luo, S. Jin, D. Wang, W. Guo, and F. Wang, "Lanebased saturation degree estimation for signalized intersections using travel time data," IEEE Intelligent Transportation Systems Magazine, vol. 9, no. 3, pp. 136-148, 2017.

[57] X. Sun, H. Zhang, W. Meng, R. Zhang, K. Li, and T. Peng, "Primary resonance analysis and vibration suppression for the harmonically excited nonlinear suspension system using a pair of symmetric viscoelastic buffers," Nonlinear Dynamics, vol. 94, 2018. 


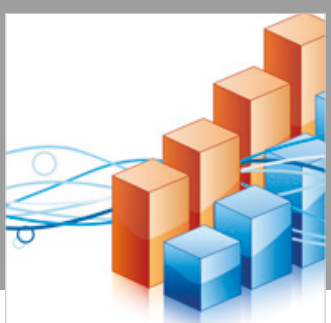

Advances in

Operations Research

\section{-n-m}
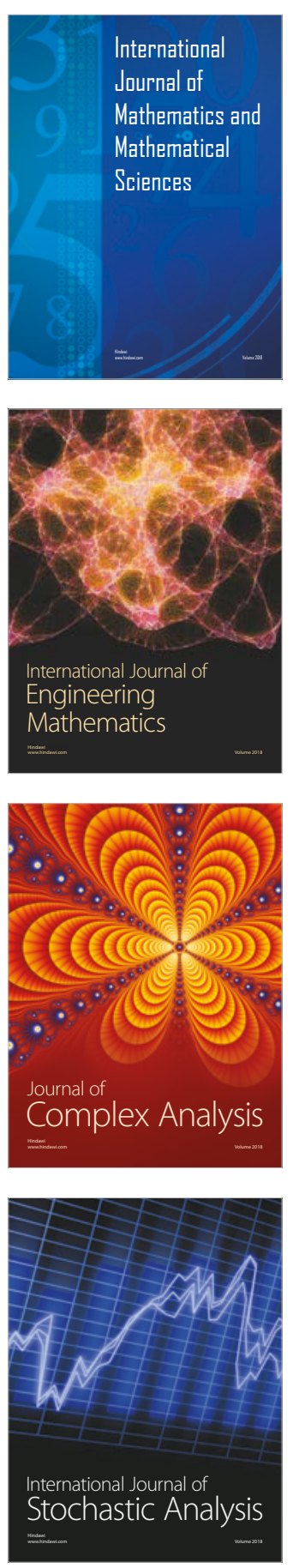
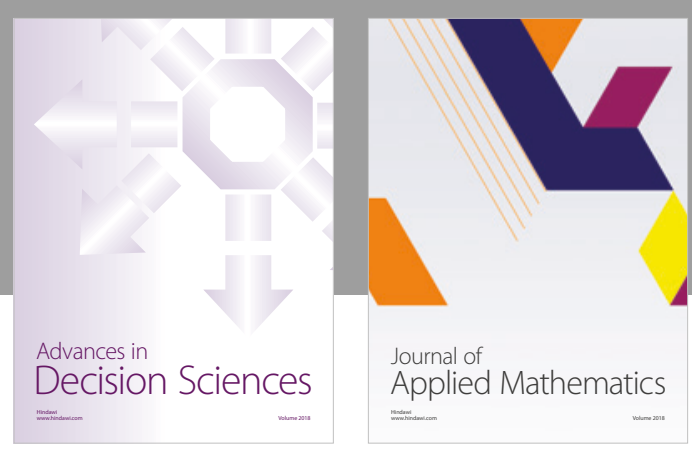

Journal of

Applied Mathematics
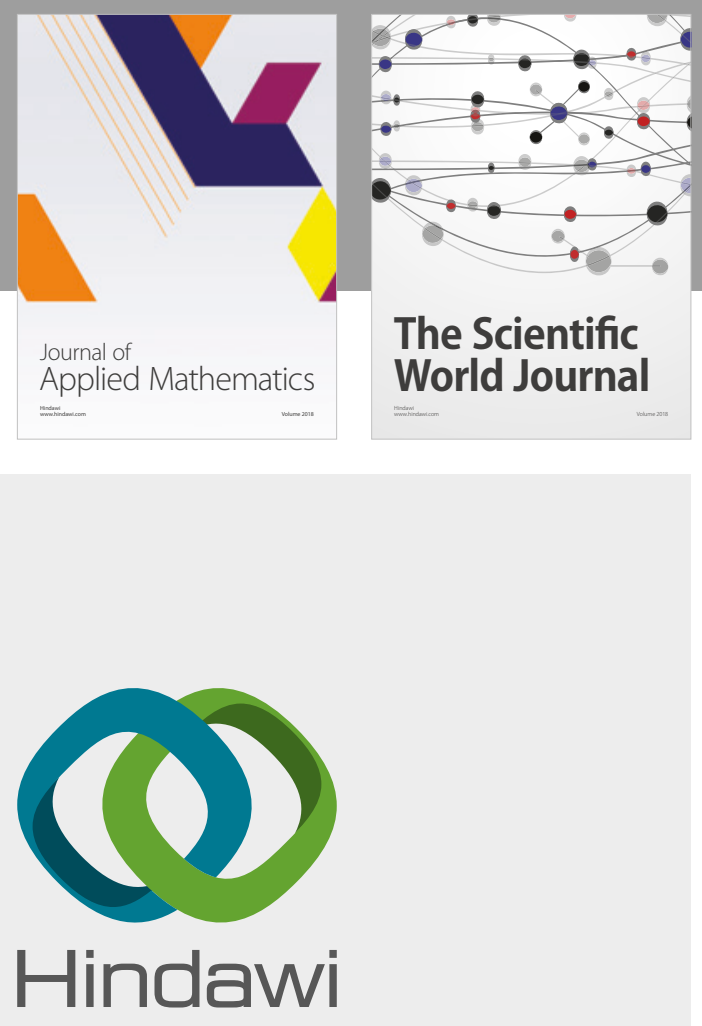

Submit your manuscripts at

www.hindawi.com

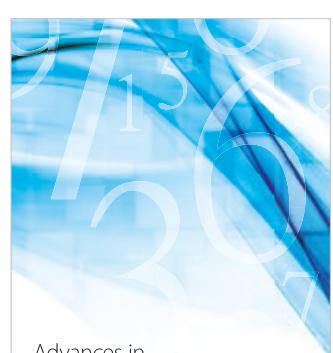

Advances in
Numerical Analysis
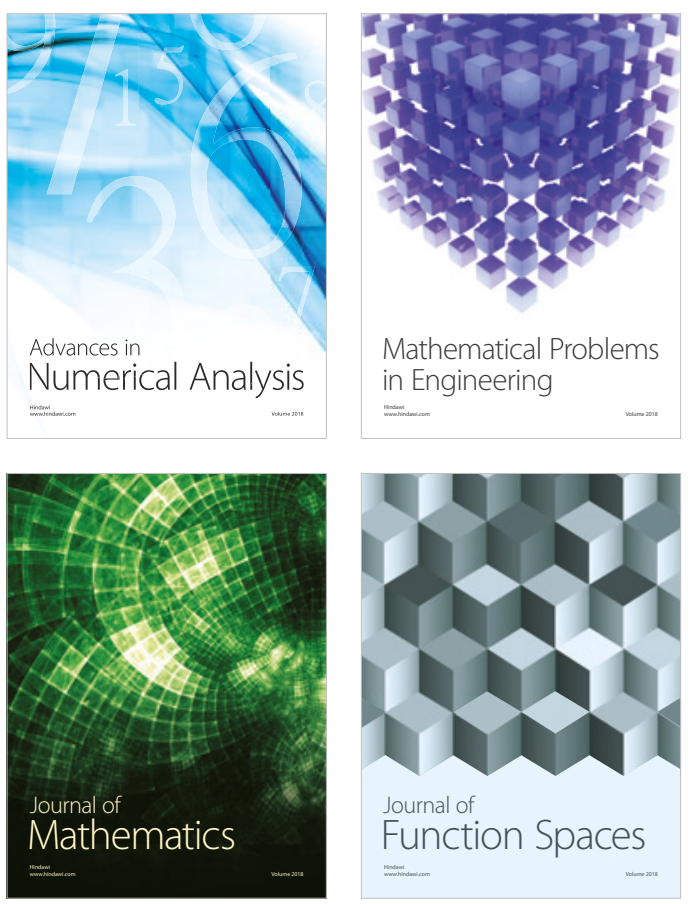

Mathematical Problems in Engineering

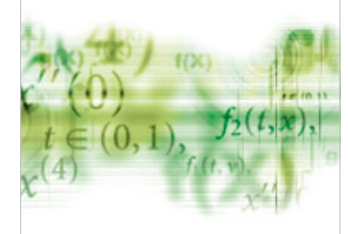

International Journal of

Differential Equations

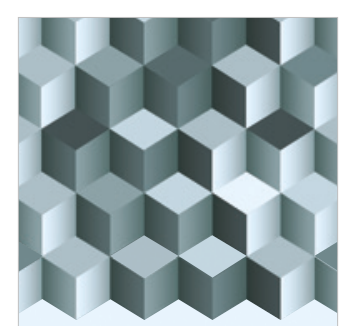

Journal of

Function Spaces
The Scientific

World Journal

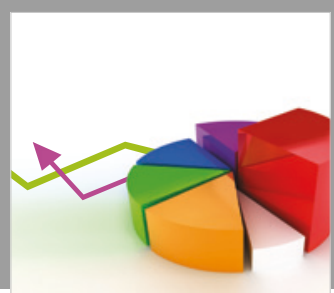

Journal of

Probability and Statistics
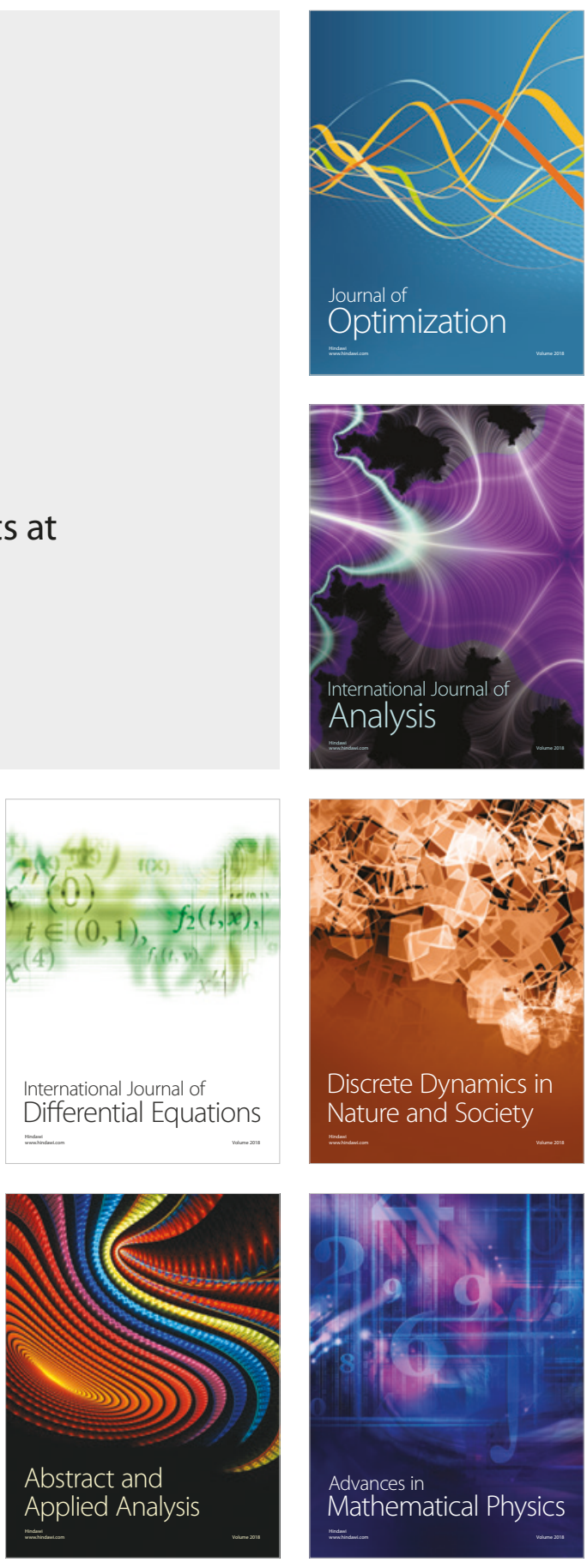